\title{
EFFECT OF CF3H AND CF3Br ON LAMINAR DIFFUSION FLAMES IN NORMAL AND MICROGRAVITY
}

\author{
B. A. VanDerWege, Michael T. Bush and Simone Hochgreb \\ Massachusetts Institute of Technology \\ Cambridge, MA
}

and

\author{
Gregory T. Linteris \\ National Institute of Standards and Technology \\ Gaithersburg, MD
}

\section{Introduction}

Chemical inhibition of diffusion flames through addition of halogenated inhibitors is a problem of significant practical and scientific interest. Extensive studies on diffusion flames in microgravity have shown that these flames have significantly different characteristics than those under normal gravity $[1,2]$. However, the mechanisms through which inhibitors reach the reaction zone to suppress combustion in diffusion flames and the effectiveness of these compounds under reduced gravity have yet to be investigated.

This study reports preliminary results of investigations on the behavior of laminar jet diffusion flames upon the addition of bromotrifluoromethane (CF3Br) and trifluoromethane $(\mathrm{CF} 3 \mathrm{H})$ to the surroundings under normal and microgravity conditions. The results show that the flame structure in microgravity is significantly different from that under normal gravity conditions, and more importantly, that conditions for flame stability are less stringent under microgravity. Experiments show that flames that cannot be stabilized under normal gravity are quite stable under microgravity conditions. In addition, normal gravity experiments at reduced pressure (low buoyancy) did not reproduce the structure or stability limits of inhibited flames in microgravity.

\section{Experiment}

Experiments were conducted in the 2.2-second drop tower at the NASA-Lewis Research Center, utilizing an existing test rig, consisting of a 27 liter closed cylindrical vessel (254 mm diameter by $533 \mathrm{~mm}$ height) provided with four sideview windows. A CCD camera (Panasonic WV-CL352) provided images of the evolution of the flame during the drop. A single jet (1.7 mm diameter) was used in the presently reported experiments. Flow rates of methane were controlled by a pressure regulator and choked flow orifice, and peak flows measured using a 0-500 sccm Omega (FMA5606-ST) mass flow meter. The flow rate of all experiments reported in this paper was $154 \mathrm{sccm}$, corresponding to a Reynolds number based on nozzle diameter of approximately 100 . The tests were performed in a quiescent chamber environment containing $0-2$ percent volume concentrations of $\mathrm{CF} 3 \mathrm{Br}$ and $0-12$ percent $\mathrm{CF} 3 \mathrm{H}$. A 2 percent methane environment was also tested for comparison with the inhibitor-laden oxidizing environment. Mixtures in the chamber were prepared by the partial pressure method, with initial evacuation and purging, followed by the addition of inhibitor, oxygen and nitrogen to the desired final pressure. Both atmospheric pressure and $0.25 \mathrm{~atm}$ tests were performed at normal and microgravity. The flames were ignited (after drop package release in microgravity experiments) by a retractable glow plug after about 20 ms of flow through the nozzle, and the images were then recorded. 
Results

\section{Atmospheric oressure experiments}

The characteristics of the flames in normal and microgravity tests performed are listed in Table 1. The structures of the normal gravity, ambient pressure flames with and without inhibitor were essentially indistinguishable. The inhibited flames, however, exhibited a more intense flicker, and it was not possible to stabilize flames at concentrations beyond $1.5 \% \mathrm{CF} 3 \mathrm{Br}$ in air at the present fuel flow rate. The structure of the diffusion flames under microgravity conditions, however, was extremely sensitive to the surrounding environment.

A typical methane laminar diffusion flame structure in microgravity is shown in Fig. 1, an oval, white, closed-tipped flame with $h / d \sim R e / 2$ [2], with the base extending around the nozzle. At atmospheric pressure, addition of any amount of inhibitor or fuel to the oxidizing environment led to the appearance of an outer flame surrounding the core fuel jet flame. The addition of $4 \%$ CF3H (by volume) to the oxizing environment led to a somewhat more pronounced outer flame, and the opening of the flame tip (Fig. 2). At higher concentrations, the main observable effect of the addition of $\mathrm{CF} 3 \mathrm{H}$ was to completely suppress the sooty region, creating a flame with a blue base and no visible tip. This behavior (suppression of soot related luminosity) is consistent with the decrease of oxygen concentrations resulting from replacement by a diluent (in this case, the inhibitor itself) [3]. However, the flame which was observed was the size and shape of outer flames recorded in other experiments with fuel or inhibitor addition, which leads us to believe that there might be an inner flame which was however too dim to be registered by the camera.

In order to determine whether the outer flame could be attributed to the consumption of the inhibitor on the air side, 2 percent of methane was added to the surrounding air under microgravity conditions. The flame had approximately the same height as the flame without addition of methane, but the tip was open and a faint light halo surrounded the main reaction zone (Fig. 4).

The addition of $\mathrm{CF} 3 \mathrm{Br}$ to the oxidizing environment under microgravity at ambient pressure produced a marked change in structure (Fig. 5). There is an obvious 'tulip' double flame structure, with a visible region significantly shorter than the uninhibited flame. An open-tipped inner flame is surrounded by a wider outer flame whose visible region ends shortly before the outer flame. Instead of the rounded base, a flat circular base slightly upstream of the nozzle tip is visible. The visible outer flame is most likely a result of $\mathrm{CF} 3 \mathrm{Br}$ reaction, supported thermally by the main inner flame. Such behavior has been observed experimentally in coflowing two dimensional diffusion flames [4], opposed jet diffusion flames [5], and surmised from numerical simulations [6]. The study in coflowing flames identified the outer visible flame spectroscopically as greenish $\mathrm{Br}_{2}$ emission. $\mathrm{A} \mathrm{Br}_{2}$ peak would be expected also from opposed stretched flame calculations [6]. The observed color of the outer flame was closer to yellow than green. It remains to be determined whether the yellow luminosity is a result of soot in the outer flame, or of the camera response at the given settings. The opening of the flame tip could be explained by the reduction in the maximum stretch supported by the diffusion flame at the tip with the addition of inhibitor [7]. However, that would not explain the flame tip opening in the case of addition of plain methane to the surroundings.

\section{Low Pressure Experiments $(0.25 \mathrm{~atm})$}

The effects of reduction in pressure on normal and microgravity flames with the addition of $\mathrm{CF} 3 \mathrm{Br}$. were explored to understand how normal gravity, weakly buoyant low pressure diffusion flames relate to microgravity flames. Experiments were performed both at nomal and microgravity in a $0.25 \mathrm{~atm}$ quiescent environment (corresponding to a reduction in buoyancy by a factor of 16) with and without the addition of CF3Br. 
Reduction of pressure at normal gravity leads to elimination of flicker at $0.25 \mathrm{~atm}$, and the presence of a stable oval white flame surrounded by a dim halo of glowing gases (Fig. 6). Addition of $1 \%$ CF3Br causes the flame to lift off the nozzle and stabilize at about $25 \mathrm{~mm}$ from the nozzle as a flat blue-white flame with a circular base and an oval tip (Fig. 7). The stabilization mechanism is probably the same as in other lifted flames, where premixing at the base aids in the establishment of a stoichiometric region. With the addition of 2 percent $\mathrm{CF} 3 \mathrm{Br}$, the flame lit but was promptly blown off.

Under microgravity conditions, however, apparently stable anchored flames (for the duration of the test) were observed for both 1 and 2 percent CF3Br addition (Figs. 8-9). The flames were oval, with closed tip, a wide blue base and a broad gas halo. The ability to stabilize these flames shows once again that both under normal and lower pressures, conditions for the extinguishment of diffusion flames at these low pressures appear to be more stringent under microgravity than at normal gravity. Therefore, experiments under weakly buoyant conditions may not capture the stability limits of flames under inhibiting environments in microgravity.

\section{Conclusions}

The present experiments with laminar jet diffusion flames burning under normal and microgravity conditions in a quiescent environment with addition of halogenated hydrocarbons have yielded the following conclusions:

1. Stability limits of flames with the addition of $\mathrm{CF} 3 \mathrm{Br}$ and $\mathrm{CF} 3 \mathrm{H}$ to the oxidizer environment under microgravity are wider than those under normal gravity.

2. The addition of inhibitors to the oxidizer under microgravity conditions creates a double flame structure. The outer flame is probably a region where the inhibitor reacts, supported by the heat release of the inner fuel flame. This behavior is particularly clear in the case of CF3Br.

3. Addition of halogenated inhibitors to $\mu$ g flames leads to shorter, open tipped flames. Addition of large amounts $(>4 \%)$ of $\mathrm{CF} 3 \mathrm{H}$ suppresses the appearance of luminous soot.

4. At low pressures $(0.25 \mathrm{~atm})$, normal gravity diffusion flames resemble their microgravity counterparts more closely. However, flames at these pressures that cannot be stabilized under normal gravity appear to be stable under microgravity.

\section{Future Work}

The goal of the project is to understand the effectiveness and action of halogenated inhibitors on the extinction of diffusion flames at reduced gravity. Additional experimental work in microgravity and ground based normal gravity experiments are planned. Numerical and analytical work to interpret and explain the experimental findings is being prepared for the near future.

The effects of diluents, oxygen and inhibitor mole fractions, different halogenated inhibitors, fuel types and jet Reynolds numbers will continue to be investigated in the 2.2-second drop tower. In addition, the study of inhibited $\mathrm{CO} / \mathrm{H} 2$ flames is also being considered, given the obvious simplification of the fuel chemistry and the absence of soot. A nomal gravity, low-pressure diffusion flame burner for normal and microgravity experiments is currently under construction at MIT. Additional diagnostics, including IR imaging, radiation measurement, and thermocouples, are being considered. Complementary experiments on the behavior of counterflow diffusion flames will be conducted at NIST this Spring to aid in the interpretation of the laminar jet flame observations.

Plans for numerical modeling of the system are: a) interpret the structure and validate chemical model for halogenated inhibitor addition using a 1D counterflow diffusion flame code; b) identify 
potential paths for reduction of the chemical mechanism and c) incorporate the reduced mechanism into a $2 \mathrm{D}$ jet diffusion flame.

\section{Acknowledgements}

The invaluable expertise and generosity of Dr. David L. Urban in permitting and assisting us with the use of an existing rig for our initial drop tower experiments is gratefully acknowledged. This work is funded under NASA Microgravity Research Grant NAG3-160. Additional support was also provided by NSF through Graduate Research Fellowships for B. A. VanDerWege and M. T. Bush.

\section{References}

1. Law, C. K. and Faeth, G. M. , "Opportunities and Challenges of Combustion in Microgravity", Prog. Combust. Sci. 20, pp. 65-113 (1994).

2. Bahadori, M. Y. and Edelman, R. B, "Effects of Buoyancy of Gas Jet Diffusion Flames", NASA Contractor Report 191109 (1993).

3. Bahadori, M. Y. and Edelman, R. B., "Effects of Oxygen Concentration on Radiative Loss from Normal Gravity and Microgravity Methane Diffusion Flames", AlAA paper 92-0243 (1992).

4. Simmons, R. F. and Wolfhard, H. G. "The Influence of Methyl Bromide on Flames, Part 2 Diffusion Flames", Trans. Far. Soc. 52, p. 53 (1956).

5. Trees, D., llincic, N., Weissweiller, T., Zamfirescu, N., Grudno, A. and Seshadri, K., "Experimental and Numerical Studies on Chemical Inhibition of Methane-Air Diffusion Flames by CF3Br and CF3H", to appear, Central States/Western States/Mexican National Sections of the Combustion Institute, April 23-26, 1995.

6. Masri, A. R. "Chemical Inhibition of Nonpremixed Flames of Hydrocarbon Fuels with CF3Br", Combust. Sci. and Tech. 96, pp 189-212 (1994).

7. Hamins, A., Trees, D., Seshadri, K. and Chelliah, H. K. "Extinction of Nonpremixed Flames with Halogenated Fire Supressants", Combust. Flame, 99, 2, pp. 221 (1994).

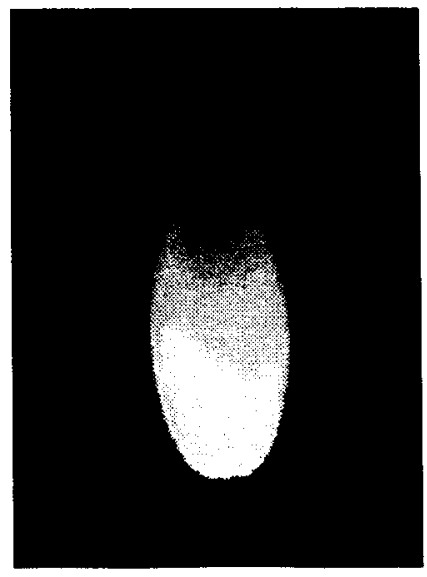

$10 \mathrm{~mm}$

Figure 1. Uninhibited $\mathrm{CH} 4$ laminar jet flame in microgravity and $1 \mathrm{~atm}(d=1.7 \mathrm{~mm}, Q=154 \mathrm{sccm}, R e=98)$. All subsequent figures show same flow conditions. 
Table 1. Summary of experimental results for inhibited $\mathrm{CH} 4$ laminar diffusion flames

(d = $1.7 \mathrm{~mm}, \mathrm{Re}=98, Q=154 \mathrm{sccm}$, fuel: methane)

\begin{tabular}{|c|c|c|c|c|}
\hline Environment ${ }^{\mathrm{a}}$ & $\mathrm{P}(\mathrm{atm})$ & $\mu g / n g$ & $h(m m)^{b}$ & Characteristics \\
\hline Air & 1.0 & $\mathrm{ng}$ & $40 \pm 10$ & Sooty with blue base. >15 Hz flieker. \\
\hline Air & 1.0 & $\mu \mathrm{g}$ & 55 & $\begin{array}{l}\text { Sooty, closed-tip, rounded base. Flame } \\
\text { transitions from yellow to red at the very tip. }\end{array}$ \\
\hline $1 \% \mathrm{CH} 4$ & 1.0 & ng & $40 \pm 10$ & $\begin{array}{l}\text { Indistinguishable from flame without } \mathrm{CH} 4 \\
\text { added. }\end{array}$ \\
\hline $2 \% \mathrm{CH} 4$ & 1.0 & $\mu g$ & 45 & $\begin{array}{l}\text { Thin, dim outer flame, core flame sooty with } \\
\text { open tip. }\end{array}$ \\
\hline $1 \% \mathrm{CF} 3 \mathrm{Br}$ & 1.0 & $\mathrm{ng}$ & $57 \pm 25$ & $\begin{array}{l}\text { Blue base shrinks and flickers. Flamelets } \\
\text { break off from the long tip. }\end{array}$ \\
\hline $1.5 \% \mathrm{CF} 3 \mathrm{Br}$ & 1.0 & ng & $75 \pm 15$ & $\begin{array}{l}\text { Flame blows off and stabilizes unsteadily at } \\
\text { about } 25 \mathrm{~mm} \text { above the nozzle with a circular } \\
\text { rim of about } 10 \mathrm{~mm} \text { in diameter. }\end{array}$ \\
\hline $2 \% \mathrm{CF} 3 \mathrm{Br}$ & 1.0 & ng & & $\begin{array}{l}\text { Flame ignites but is blown off almost } \\
\text { immediately. }\end{array}$ \\
\hline $1 \% \mathrm{CF} 3 \mathrm{Br}$ & 1.0 & $\mu g$ & $\begin{array}{l}38 \text { (inner) } \\
27 \text { (outer) }\end{array}$ & $\begin{array}{l}\text { Obvious double (inner-outer) flame structure. } \\
\text { Inner flame is open tipped and about } 20 \mathrm{~mm} \text { in } \\
\text { width. The outer flame is about } 30 \mathrm{~mm} \text { wide and } \\
\text { sorter, with apparent flat blue base of about } 10 \\
\mathrm{~mm} \text { diameter. }\end{array}$ \\
\hline $1.5 \% \mathrm{CF} 3 \mathrm{Br}$ & 1.0 & $\mu g$ & $\begin{array}{l}38 \text { (inner) } \\
25 \text { (outer) } \\
\end{array}$ & Very similar to $1 \% \mathrm{CF} 3 \mathrm{Br}$ flame. \\
\hline 4 and $8 \%$ CF $3 \mathrm{H}$ & 1.0 & ng & $\begin{array}{l}45 \pm 12 l \\
50 \pm 15\end{array}$ & $\begin{array}{l}\text { Similar to uninhibited flame, with larger blue } \\
\text { base and intense flickering. }\end{array}$ \\
\hline $4 \% \mathrm{CF} 3 \mathrm{H}$ & 1.0 & $\mu g$ & 45 & $\begin{array}{l}\text { Dim but visible double flame structure. Inner } \\
\text { flame is about } 25 \mathrm{~mm} \text { wide, orange and more } \\
\text { diffuse than base flames, with a wide open tip. } \\
\text { Outer flame is visible only near the base. }\end{array}$ \\
\hline 8 and $12 \%$ & 1.0 & $\mu \mathrm{g}$ & $\begin{array}{l}25 \\
\text { (outer?) }\end{array}$ & $\begin{array}{l}\text { Visible flame region is } 30 \mathrm{~mm} \text { wide, with a } \\
\text { conical blue base and apparently no soot, } \\
\text { possibly due to the reduced oxygen } \\
\text { concentrations under the high inhibitor mole } \\
\text { fractions. }\end{array}$ \\
\hline Air & 0.25 & $\mathrm{ng}$ & 30 & $\begin{array}{l}\text { Oval white/blue flame surrounded by a thin } \\
\text { halo of dimly glowing gasses. }\end{array}$ \\
\hline $1 \%$ CF $3 B$ r & 0.25 & ng & 25 & $\begin{array}{l}\text { Flame has a wide circular base lifted about } 30 \\
\text { mm off nozzle, blue-white with oval tip. At } 2 \% \text {, } \\
\text { flame lights and immediately blows off. }\end{array}$ \\
\hline 1 and $2 \% \mathrm{CF} 3 \mathrm{Br}$ & 0.25 & $\mu g$ & $57 / 65$ & $\begin{array}{l}\text { Closed tip oval blue-white flame with bottom } \\
\text { half blue and upper half sooty, with a fairly } \\
\text { broad halo of glowing gasses. At } 2 \% \text {, the halo } \\
\text { is brighter, and a larger fraction of the flame } \\
\text { white. }\end{array}$ \\
\hline
\end{tabular}

a) Balance air: $0.21 \% 02,0.79 \% \mathrm{~N} 2$

b) For flickering flames, average height. For lifted flames, height is measured from flame base, not nozzle. 

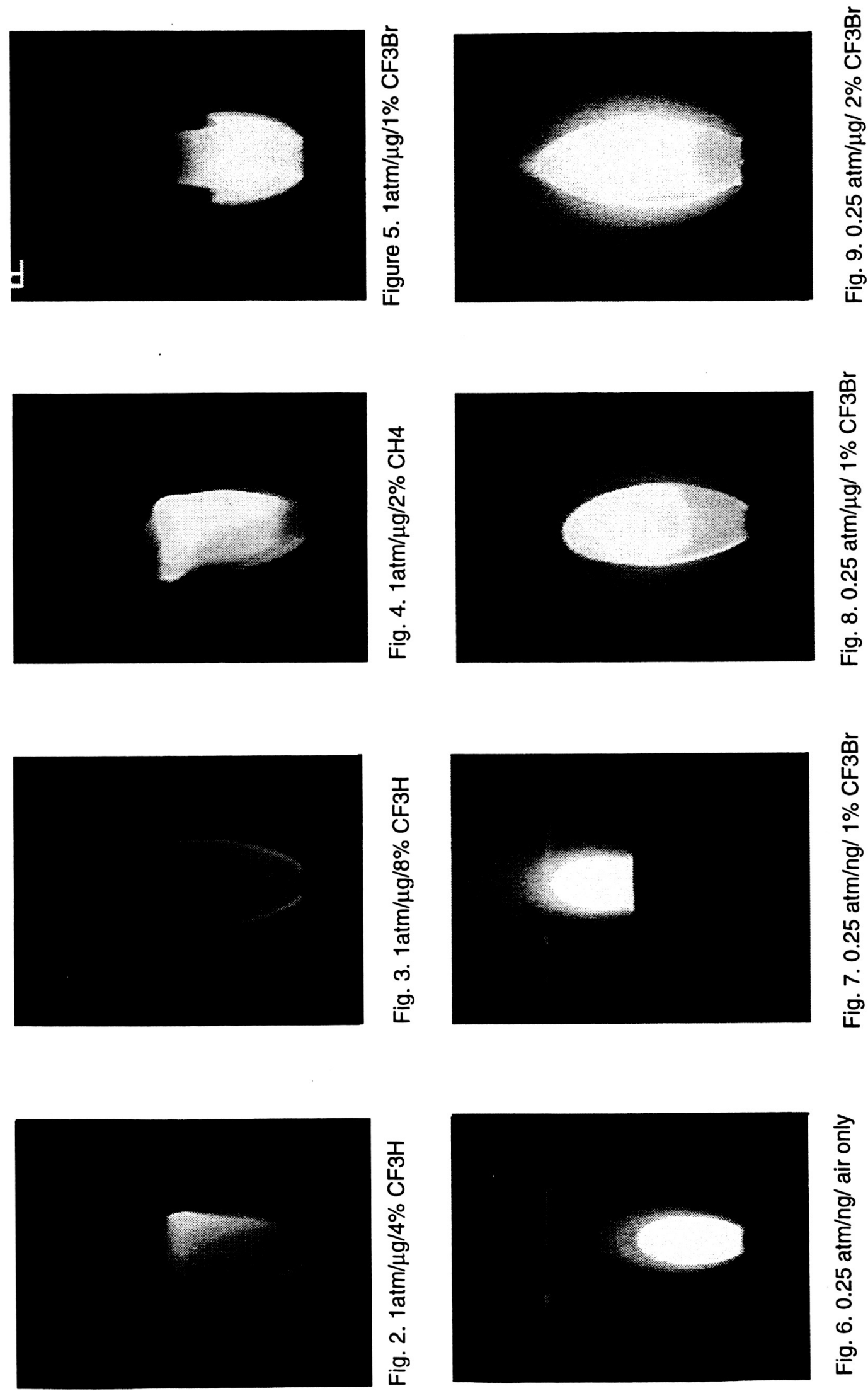